\title{
A Comparison of Open and Laparoscopic-assisted Colectomy for Obstructive Colon Cancer
}

\author{
HIROSHI TAMAGAWA ${ }^{1 *}$, TORU AOYAMA ${ }^{1 *}$, MASAKATSU NUMATA $^{1}$, KEISUKE KAZAMA $^{1}$, \\ YUKIO MAEZAWA ${ }^{1}$, YOSUKE ATSUMI ${ }^{1}$, KENTARO HARA ${ }^{1}$, SHINNOSUKE KAWAHARA $^{1}$, KAZUKI KANO ${ }^{1}$, \\ NORIO YUKAWA ${ }^{1}$, HIROYUKI SAEKI ${ }^{2}$, TENI GODAI $^{3}$, YASUSHI RINO ${ }^{1}$ and MUNETAKA MASUDA ${ }^{1}$ \\ ${ }^{1}$ Department of Surgery, Yokohama City University, Yokohama, Japan; \\ ${ }^{2}$ Department of Surgery, Yokohama Minamikyousai Hospital, Yokohama, Japan; \\ ${ }^{3}$ Department of Surgery, Fujisawashonandai Hospital, Fujisawa, Japan
}

\begin{abstract}
Background/Aim: We performed a retrospective multi-center cohort analysis to compare the outcomes of laparoscopic surgery vs. open surgery for obstructive colon cancer. Patients and Methods: A total of 455 patients with colon cancer with ileus underwent surgery at Yokohama City University Hospital and four related institutions from April 2000 to March 2016. Results: There were 414 cases in the open surgery group and 41 cases in the laparoscopic surgery group with no marked differences in the gender or age. The postoperative complication rate, according to the ClavienDindo classification, was lower in the laparoscopic group compared to the open surgery group. The postoperative hospital stay was 16 days in the open surgery group and 9 days in the laparoscopic surgery group ( $p=0.004)$. Among the various factors examined, the operation approach was identified as a statistically significant independent risk factor for postoperative complications ( $p=0.015)$. Conclusion: Preoperative treatment for colon cancer with ileus and elective laparoscopic surgery are thought to be useful for achieving curative treatment, avoiding colostomy, and shortening the length of hospital stay.
\end{abstract}

Colorectal cancer (CRC) remains the third most common cause of mortality and cancer-specific cause of death worldwide (1). It has been reported that $10 \%-29 \%$ of colon cancer have bowel obstruction (2-4). Emergency surgery,

This article is freely accessible online.

*These Authors contributed equally to this study.

Correspondence to: Hiroshi Tamagawa, Department of Surgery, Yokohama City University, 3-9 Fukuura, Kanazawa, Yokohama 236-0004, Japan. Tel: +81 457872645, Fax: +81 457860226, e-mail: rinta77-nosuke@amber.plala.or.jp

Key Words: Short-term outcomes, obstructive colon cancer, laparoscopic-assisted colectomy. such as Hartmann's procedure or palliative diverting colostomy construction, is usually performed for obstructive CRC because of the high mortality rate of $10 \%$ to $28 \%$ and the high incidence of postoperative complications (5).

Laparoscopic-assisted colectomy is an established minimally invasive procedure first reported in 1991. However, in many cases with ileus, conventional open surgeries are often performed, due to the narrowness of the intraperitoneal working space and the risk of injuring the dilated intestinal tract during laparoscopic manipulation. Since local lesions with occlusion are often of an advanced stage and bulky, subsequent laparoscopic resection of tumors may be associated with increased technical difficulty, leading to increased rates of morbidity and conversion.

Recently, it has become possible to preoperatively decompress the intestinal tract using a transanal tube and perform elective surgery as a bridge to surgery without reducing the quality of life using a colonic stent for obstructive CRC. However, whether or not temporary bowel decompression by preoperative treatment, such as with a colonic stent and ileus tube, allows patients with colonic obstruction to undergo laparoscopic resection safely remains unclear.

In this study, we performed a retrospective multi-center cohort analysis to compare the outcomes of laparoscopic surgery $v s$. open surgery for obstructive colon cancer and evaluate the safety and usefulness of laparoscopic colectomy with preoperative decompression treatment.

\section{Patients and Methods}

Patients. This retrospective multi-center study was performed using data from a prospectively maintained database of patients with colon obstruction undergoing colorectal cancer surgery at the Yokohama City University, Department of Surgery, and its affiliated institutions between April 2008 and March 2018.

Surgical procedure. According to the guidelines of the 2016 Japanese Society for Cancer of the Colon and Rectum (6), radical colectomy 
Table I. Demographic and clinicopathological factors.

\begin{tabular}{|c|c|c|c|c|c|c|c|}
\hline & \multicolumn{2}{|c|}{ All cases } & \multicolumn{2}{|c|}{ Open } & \multicolumn{2}{|c|}{ Laparoscopic } & \multirow[b]{2}{*}{$p$-Value } \\
\hline & Number & $\%$ & Number & $\%$ & Number & $\%$ & \\
\hline Age(year) & & & & & & & 0.914 \\
\hline$<70$ & 174 & 38.2 & 158 & 38.2 & 16 & 39.0 & \\
\hline$\geq 70$ & 281 & 61.8 & 256 & 61.8 & 25 & 61.0 & \\
\hline Gender & & & & & & & 0.216 \\
\hline Male & 235 & 51.8 & 210 & 50.8 & 25 & 61.0 & \\
\hline Female & 219 & 48.2 & 203 & 49.2 & 16 & 39.0 & \\
\hline BMI & & & & & & & 0.338 \\
\hline$<22$ & 211 & 56.4 & 185 & 55.6 & 26 & 63.4 & \\
\hline$\geq 22$ & 163 & 43.6 & 148 & 44.4 & 15 & 36.6 & \\
\hline ASA-PS & & & & & & & 0.047 \\
\hline $1-2$ & 308 & 72.1 & 273 & 70.7 & 35 & 85.4 & \\
\hline $3-4$ & 119 & 27.9 & 56 & 29.3 & 6 & 14.6 & \\
\hline ECOG-PS & & & & & & & $<0.001$ \\
\hline 0 & 116 & 47.3 & 113 & 42.4 & 29 & 72.5 & \\
\hline $1-3$ & 129 & 52.7 & 118 & 57.6 & 11 & 27.5 & \\
\hline Location & & & & & & & 0.563 \\
\hline Ascending & 143 & 31.4 & 128 & 30.9 & 15 & 36.6 & \\
\hline Transverse & 72 & 15.8 & 68 & 16.4 & 4 & 9.8 & \\
\hline Descending & 60 & 13.2 & 56 & 13.5 & 4 & 9.8 & \\
\hline Sigmoid & 180 & 39.6 & 162 & 39.1 & 18 & 43.9 & \\
\hline Tumor size & & & & & & & 0.402 \\
\hline$<70$ & 312 & 76.7 & 280 & 76.1 & 32 & 82.1 & \\
\hline$\geq 70$ & 95 & 23.3 & 88 & 23.9 & 7 & 17.9 & \\
\hline pT & & & & & & & 0.044 \\
\hline $0-3$ & 200 & 47.6 & 187 & 49.2 & 13 & 32.5 & \\
\hline 4 & 220 & 52.4 & 193 & 50.8 & 27 & 67.5 & \\
\hline $\mathrm{pN}$ & & & & & & & 0.819 \\
\hline Negative & 192 & 46.7 & 174 & 46.9 & 18 & 45.0 & \\
\hline Positive & 219 & 53.3 & 197 & 53.1 & 22 & 55.0 & \\
\hline
\end{tabular}

Numbers in bold indicate statistically significant differences.

and lymph node resection were performed. Hand-sewn functional endto-end anastomosis was performed according to the tumor location.

Definition of postoperative surgical complications. Postoperative surgical complications were retrospectively determined from the patients' records according to the Clavien-Dindo classification (7).

Evaluations and statistical analyses. The patients were divided into a laparoscopic-assisted surgery group and open surgery group. Pearson's chi-square test or Fisher's exact test was used to compare the baseline characteristics between the two groups. The risk factors for morbidity were analyzed by binominal logistic regression. Linear regression models were fitted to the multivariate analysis. $p$ Values of $<0.05$ were considered statistically significant.

The IBM SPSS (version 21.0; SPSS Inc., Chicago, IL, USA) software package was used for all statistical analyses. This study was approved by the Institutional Review Board of each institution.

\section{Results}

Patients. We evaluated 455 patients in the present study. Table I shows the clinicopathological characteristics of the patients. There were 414 cases in the open surgery group and 41 cases in the laparoscopic surgery group. The patients' ages ranged from 37-99 years (median: 73 years), and 235 patients were male while 219 were female. There was no marked difference in the body mass index between the two groups or in the American Society of Anesthesiologists physical status (ASA-PS) or Eastern Cooperative Oncology Group- Performance Status (ECOG-PS), although the laparoscopic surgery group patients were overall in a better condition than those in the open surgery group.

The surgical findings are shown in Table II. The laparoscopic surgery group showed a significantly longer surgery duration than the open surgery group (188 vs. 153 min, $p=0.007)$ but significantly less blood loss (10 vs. 100 $\mathrm{ml} ; p<0.001)$. In addition, the laparoscopic surgery group showed more cases of curative resection, although the difference was not statistically significant $(82.5 \% v s .70 .0 \%$, $p=0.096$ ), and more lymph nodes were dissected than in the open surgery group (23 vs. 17; $p=0.004)$. Preoperative treatment for ileus (ileus tube: 112 cases, nasogastric tube: 2 
Table II. Operative results.

\begin{tabular}{lccc}
\hline & $\begin{array}{c}\text { Open } \\
\mathrm{n}=414\end{array}$ & $\begin{array}{c}\text { Laparoscopic } \\
\mathrm{n}=41\end{array}$ & $p$-Value \\
\hline Operation time (min) & $153(57-415)$ & $188(85-307)$ & $\mathbf{0 . 0 0 7}$ \\
Intraoperative bleeding (g) & $100(5-2500)$ & $10(0-371)$ & $<\mathbf{0 . 0 0 1}$ \\
Lymph node dissection & $244 / 160$ & $11 / 30$ & $\mathbf{< 0 . 0 0 1}$ \\
$\begin{array}{l}\text { (D2/D3) } \\
\text { Number of dissected LN }\end{array}$ & $17(0-67)$ & $23(1-77)$ & $\mathbf{0 . 0 0 4}$ \\
Emergency operation & $85(20.5 \%)$ & $0(0 \%)$ & $\mathbf{0 . 0 0 1}$ \\
Preoperative treatment & $129(35.6 \%)$ & $21(51.2 \%)$ & $\mathbf{0 . 0 4 9}$ \\
Curability (R0 or 1/R2) & $33 / 7(82.5 \%)$ & $282 / 121(70.0 \%)$ & 0.096 \\
\hline
\end{tabular}

Numbers in bold indicate statistically significant differences.

cases, colonic stent: 28 cases) was performed more frequently in the laparoscopic surgery group than in the open surgery group $(51.2 \%$ vs. $35.6 \%, p=0.049)$

Short-term outcomes. Table III shows the clinical short-term outcomes. The rate of colostomy was significantly lower in the laparoscopic surgery group than in the open surgery group $(5.0 \%$ vs. $24.8 \%, p=0.005)$. The postoperative complication rate was lower in the laparoscopic surgery group in all cases with a Clavien-Dindo classification than in the open surgery group. The postoperative hospital stay was significantly shorter in the laparoscopic surgery group than in the open surgery group ( 9 vs. 16 days, $p=0.004$ ).

Risk factors for surgical morbidity. The risk factors for surgical morbidity were analyzed by univariate and multivariate analyses using the pre- and postoperative factors. The results are shown in Table IV. Among the factors examined, the operation approach was identified as a statistically significant independent risk factor for postoperative complications $(p=0.015)$.

\section{Discussion}

In this multicenter study, we retrospectively analyzed the clinical safety and technical feasibility of the elective laparoscopic approach with obstructing colon carcinoma, including the rate of colostomy, hospital stay, and postoperative complications. Conventional emergency Hartmann's operation and subsequent colostomy closure carries a high mortality and morbidity rate compared with elective operations (8). Placing an endoscopic stent for colonic obstruction can help avoid the need for emergency surgery and allow elective surgery to be performed.

Recent studies support the endoscopic placement of a colonic stent to relieve colonic obstruction (9). Colonic stents have been shown to be a highly effective and safe therapy for relieving colonic obstruction with less acute
Table III. Short-term outcomes.

\begin{tabular}{lccc}
\hline & $\begin{array}{c}\text { Open } \\
\mathrm{n}=414\end{array}$ & $\begin{array}{c}\text { Laparoscopic } \\
\mathrm{n}=41\end{array}$ & $p$-Value \\
\hline Hospital stay & $16(7-206)$ & $9(5-27)$ & $\mathbf{0 . 0 0 1}$ \\
Colostomy & $101(24.8 \%)$ & $2(5.0 \%)$ & $\mathbf{0 . 0 0 5}$ \\
Complications (Grade I) & $158(38.2 \%)$ & $6(14.6 \%)$ & $\mathbf{0 . 0 0 3}$ \\
Complications (Grade II) & $111(26.8 \%)$ & $4(9 \%)$ & $\mathbf{0 . 0 1 7}$ \\
Complications (Grade III) & $59(14.3 \%)$ & $1(2.4 \%)$ & $\mathbf{0 . 0 3 3}$ \\
\hline
\end{tabular}

Numbers in bold indicate statistically significant differences.

mortality and morbidity than in patients who undergo emergent surgical decompression for malignant colonic obstruction (10-12). In addition, decompression of the obstructed section of the colon after stent insertion allows patients to eat, and elective surgery can improve the nutritional status of patients.

In our study, the laparoscopic surgery group had a significantly longer operative time and less blood loss than the open surgery group. In addition, the laparoscopic surgery group had a higher rate of curative resection, and more lymph nodes were dissected compared to the open surgery group. Furthermore, treatment for preoperative colonic obstruction, such as colonic stent, avoided emergency surgery and allowed laparoscopic surgery to be scheduled.

Recently, colonic stents have been used to improve the safety of laparoscopic-assisted surgery for patients with obstructing CRC. The endoscopic release of the obstruction allows for the improvement of the patient's condition, which leads to more accurate preoperative staging and safer bowel preparation (13). The higher rate of lymph node harvest in the elective endo-laparoscopic group might reflect suboptimal oncologic surgery in the obstructed colon in an emergency setting, where surgeons might focus more on relieving the obstruction than on curing the cancer (14).

In our study, the laparoscopic group achieved better shortterm postoperative results than the open surgery group. The rate of colostomy and the postoperative hospital stay were significantly shorter in the laparoscopic surgery group than in the open group. The reduced rate of permanent stoma creation in the laparoscopic group may translate to a better quality of life after surgery and a short hospital stay $(15,16)$. In addition, the postoperative complication rate for the laparoscopic surgery group was significantly lower than that for the open surgery group. Some studies have achieved similar results. Stipa et al. (17) have reported that the morbidity in the open surgery group was significantly higher than that in the laparoscopic-assisted surgery group, and Cheung et al. (18) have reported that primary anastomosis was possible in all elective laparoscopic surgery patients, including four cases of temporary ileostomy. 
Table IV. Uni- and Multi-variate Cox proportional hazards analysis of clinicopathological factors for complications.

\begin{tabular}{|c|c|c|c|c|c|c|}
\hline & \multicolumn{3}{|c|}{ Univariate analysis } & \multicolumn{3}{|c|}{ Multivariate analysis } \\
\hline & Hazard ratio & $95 \% \mathrm{CI}$ & $p$-Value & Hazard ratio & $95 \% \mathrm{CI}$ & $p$-Value \\
\hline Gender & & $0.985-2.113$ & 0.060 & & $0.712-2.613$ & 0.447 \\
\hline Female & 1 & & & 1 & & \\
\hline Male & 1.449 & & & 1.241 & & \\
\hline Age & & $0.731-1.675$ & 0.631 & & & \\
\hline$<70$ & 1 & & & & & \\
\hline$\geq 70$ & 1.107 & & & & & \\
\hline Location & & $0.722-1.554$ & 0.77 & & & \\
\hline Left side & 1 & & & & & \\
\hline Right side & 1.059 & & & & & \\
\hline pT & & $0.780-1.730$ & 0.462 & & & \\
\hline $1-3$ & 1 & & & & & \\
\hline 4 & 1.161 & & & & & \\
\hline $\mathrm{pN}$ & & $0.774-1.728$ & 0.478 & & & \\
\hline Negative & 1 & & & & & \\
\hline Positive & 1.157 & & & & & \\
\hline ECOG-PS & & $0.917-2.754$ & 0.099 & & $0.779-2.418$ & 0.275 \\
\hline 0 & 1 & & & 1 & & \\
\hline $1-3$ & 1.589 & & & 1.372 & & \\
\hline Operation & & $1.481-8.753$ & 0.005 & & $1.269-9.300$ & 0.015 \\
\hline Laparoscopic & 1 & & & 1 & & \\
\hline Open & 3.600 & & & 3.436 & & \\
\hline
\end{tabular}

Numbers in bold indicate statistically significant differences.

Special attention is required when interpreting the current results, as there are some potential limitations associated with this study. First, this was a retrospective study. Our findings may therefore have been observed merely by chance in this series. Second, there may have been selection bias in the present study. Inexperienced surgeons or institutions might have avoided performing laparoscopic-assisted surgery in certain patients. Third, there was a time bias in this study, as the data were collected at institutions between 2008 and 2018. The surgical procedures and perioperative care might have changed over this period. Fourth, because the present study only analyzed on Eastern cohort, further studies should focus on a Western cohort. Given these limitations, the current results should be validated by another study.

In conclusion, laparoscopic-assisted colectomy with proper preoperative obstruction release for obstructing colonic carcinoma is safe and feasible. Compared with the open approach, the patients in our laparoscopic-assisted surgery group suffered less blood loss, avoided colostomy, and achieved a shortened hospital stay and possibly a lower morbidity rate.

\section{Conflicts of Interest}

The Authors have no conflicts of interest to declare regarding this study.

\section{Authors' Contributions}

Hiroshi Tamagawa and Toru Aoyama made substantial contributions to conception and design. Masakatsu Numata, Keisuke Kazama, Yukio Maezawa, Yosukea Atsumi, Kentaro Hara, Kazuki. Kanoa, Norio Yukawa, Hiroyuki Saeki, Teni Godai, Yasushi Rino, and Munetaka Masuda made substantial contributions to acquisition of data, or analysis and interpretation of data. Hiroshi Tamagawa and Toru Aoyama have been involved in drafting the manuscript or revising it critically for important intellectual content. Norio Yukawa, Toru Aoyama, Hiroshi Tamagawa, Yosuke Atsumi, and Shinnosuke Kawahara have given final approval of the version to be published. Each author should have participated sufficiently in the work to take public responsibility for appropriate portions of the content; and agreed to be accountable for all aspects of the work in ensuring that questions related to the accuracy or integrity of any part of the work are appropriately investigated and resolved. All authors read and approved the final manuscript.

\section{Acknowledgements}

This work was supported, in part, by the nongovernmental organization Yokohama Surgical Research Group, Dr. Masumi Kamachi (Tokyo Shinagawa Hospital), Dr. Ryuji Tominaga (Fukuoka Wajiro Hospital), Dr. Nobuko Yoshiki (Yoshiki Dermatology Clinic Ginza). The Authors express their sincere gratitude to Ms. Akiko Yoshida, Ms. Yuka Maruyama, Ms. Minako Igarashi and Ms. Mariko Yamauchi for their excellent data management in this study. 


\section{References}

1 Edwards BK, Noone AM, Mariotto AB, Simard EP, Boscoe FP, Henley SJ, Jemal A, Cho H, Anderson RN, Kohler BA, Eheman CR and Ward EM: Annual Report to the Nation on the status of cancer, 1975-2010, featuring prevalence of comorbidity and impact on survival among persons with lung, colorectal, breast, or prostate cancer. Cancer 120: 1290-314, 2014. PMID: 24343171. DOI: $10.1002 /$ cncr.28509

2 Abdussamet Bozkurt M, Gonenc M, Kapan S, Kocatasş A, Temizgönül B and Alis H: Colonic stent as bridge to surgery in patients with obstructive left-sided colon cancer. JSLS pii: e2014.00161, 2014. PMID: 25408602. DOI: 10.4293/JSLS. 2014.00161

3 van den Berg MW, Ledeboer M, Dijkgraaf MG, Fockens P, ter Borg F and van Hooft JE: Long-term results of palliative stent placement for acute malignant colonic obstruction. Surg Endosc 29: 1580-1585, 2015. PMID: 25294532. DOI: 10.1007/s00464014-3845-7

4 Ohtani H, Maeda K, Nomura S, Shinto O, Mizuyama Y, Nakagawa H, Nagahara H, Shibutani M, Fukuoka T, Amano R, Hirakawa $\mathrm{K}$ and Ohira M: Meta-analysis of robot-assisted versus laparoscopic surgery for rectal cancer. In Vivo 32: 611-623, 2018. PMID: 29695568.

5 Kim IY, Kim BR and Kim YW: Outcomes of laparoscopic and open surgery for colorectal cancer in the emergency setting. In Vivo 29: 295-300, 2015. PMID: 25792660.

6 Watanabe T, Muro K, Ajioka Y, Hashiguchi Y, Ito Y, Saito Y, Hamaguchi T, Ishida H, Ishiguro M, Ishihara S, Kanemitsu Y, Kawano H, Kinugasa Y, Kokudo N, Murofushi K, Nakajima T, Oka S, Sakai Y, Tsuji A, Uehara K, Ueno H, Yamazaki K, Yoshida M, Yoshino T, Boku N, Fujimori T, Itabashi M, Koinuma N, Morita T, Nishimura G, Sakata Y, Shimada Y, Takahashi K, Tanaka S, Tsuruta O, Yamaguchi T, Yamaguchi N, Tanaka T, Kotake K and Sugihara K; Japanese Society for Cancer of the Colon and Rectum: Japanese Society for Cancer of the Colon and Rectum (JSCCR) guidelines 2016 for the treatment of colorectal cancer. Int J Clin Oncol 23: 1-34, 2018. PMID: 28349281. DOI: 10.1007/s10147-017-1101-6

7 Clavien PA, Barkun J, de Oliveira ML, Vauthey JN, Dindo D, Schulick RD, de Santibañes E, Pekolj J, Slankamenac K, Bassi C, Graf R, Vonlanthen R, Padbury R, Cameron JL and Makuuchi M: The Clavien-Dindo classification of surgical complications: five-year experience. Ann Surg 250: 187-196, 2009. PMID: 19638912. DOI: 10.1097/SLA.0b013e3181b13ca2

8 Anderson JH, Hole D and McArdle CS: Elective versus emergency surgery for patients with colorectal cancer. Br J Surg 79: 706-709, 1992. PMID: 1379508.

9 Siddiqui A, Cosgrove N, Yan LH, Brandt D, Janowski R, Kalra A, Zhan T, Baron TH, Repici A, Taylor LJ and Adler DG: Longterm outcomes of palliative colonic stenting versus emergency surgery for acute proximal malignant colonic obstruction: a multicenter trial. Endosc Int Open 5: E232-E238, 2017. PMID: 28367495. DOI: $10.1055 / \mathrm{s}-0043-102403$
10 Repici A, De Caro G, Luigiano C, Fabbri C, Pagano N, Preatoni P, Danese S, Fuccio L, Consolo P, Malesci A, D'Imperio N and Cennamo V: WallFlex colonic stent placement for management of malignant colonic obstruction: a prospective study at two centers. Gastrointest Endosc 67: 77-84, 2008. PMID: 18155427.

11 Baron TH, Dean PA, Yates MR 3rd, Canon C and Koehler RE: Expandable metal stents for the treatment of colonic obstruction: techniques and outcomes. Gastrointest Endosc 47: 277286,1998. PMID: 9540883.

12 Baqué P, Chevallier P, Karimdjee Solihi F, Rahili MA, Iannelli A, Benizri EI, Bernard JL, Bereder JM, Oddo F, Padovani B, Gugenheim J, Benchimol D and Bourgeon A: [Colostomy vs self-expanding metallic stents: comparison of the two techniques in acute tumoral left colonic obstruction]. Ann Chir 129: 353358, 2004. PMID: 15297225.

$13 \mathrm{Ng}$ SS, Yiu RY, Li JC, Chan CK, Ng CF and Lau JY: Endolaparoscopic left hemicolectomy and synchronous laparoscopic radical nephrectomy for obstructive carcinoma of the descending colon and renal cell carcinoma. J Laparoendosc Adv Surg Tech A 16: 297-300, 2006. PMID: 16796445.

14 Oshodi TO: Colostomy is no longer appropriate in the management of uncomplicated large bowel obstruction: true or false? Ann R Coll Surg Engl 75: 301-302, 1993. PMID: 19311440.

15 Dominitz JA and Provenzale D: Patient preferences and quality of life associated with colorectal cancer screening. Am J Gastroenterol 92: 2171-2178, 1997. PMID: 9399747.

16 Sprangers MA, Taal BG, Aaronson NK and te Velde A: Quality of life in colorectal cancer. Stoma vs. nonstoma patients. Dis Colon Rectum 38: 361-369, 1995. PMID: 7720441.

17 Stipa F, Pigazzi A, Bascone B, Cimitan A, Villotti G, Burza A and Vitale A: Management of obstructive colorectal cancer with endoscopic stenting followed by single-stage surgery: open or laparoscopic resection? Surg Endosc 22: 1477-1481, 2008. PMID: 18027039.

18 Cheung HY, Chung CC, Tsang WW, Wong JC, Yau KK and Li MK: Endolaparoscopic approach vs conventional open surgery in the treatment of obstructing left-sided colon cancer: a randomized controlled trial. Arch Surg 144: 1127-1132, 2009. PMID: 20026830. DOI: 10.1001/archsurg.2009.216
Received April 24, 2020

Revised May 8, 2020

Accepted May 11, 2020 